\title{
Migrating Dental Implants Into the Maxillary Sinus; Evaluation of Different Direct Trans-Oral Surgical Approaches
}

\author{
Zaid Hamdoon ( $\square$ zothman@sharjah.ac.ae ) \\ University of Sharjah \\ Nazhat Mahmood \\ University of Mustansiriyah \\ Wael Talat \\ University of Sharjah \\ Abier Abdul Sattar \\ University of Sharjah \\ Karrar Naeim \\ Iraqi Ministry of Health \\ Ahmed Qais \\ Iraqi Ministry of Health \\ Waad Kheder \\ University of Sharjah \\ Waseem Jerjes \\ North end medical center-London
}

\section{Research}

Keywords: Displaced dental implant, Caldwell-Luc, Migrating dental implant, Maxillary sinus.

Posted Date: August 4th, 2020

DOI: https://doi.org/10.21203/rs.3.rs-48774/v1

License: (c) (i) This work is licensed under a Creative Commons Attribution 4.0 International License. Read Full License 


\section{Abstract}

Background: Dental implant surgery in atrophied maxilla has many risks, in some patients simultaneous sinus lifting with implant placement must be performed to increase the chances of successful implant which can cause implant migration. The aim of this study was to illustrate different surgical approaches to remove displaced dental implants into the maxillary sinus.

Methods: Eleven patients were diagnosed with implant migration into the maxillary sinus. Radiographs were taken to identify the exact location of these implants which showed that they can be displaced in four anatomical area: sinus floor above the alveolar bone, near the junction of the sinus and nasal floor, near the floor of the orbit, and the most posterior aspect the sinus. The surgical removal was performed through four different trans-oral approaches depending on the location of the displaced implant. The surgical challenges, duration of surgery and postoperative complications were reported.

Results: The least challenging surgical intervention was noted when removing the displaced implants from the floor of the sinus. More challenges were experienced during the surgical removal of anteriorly displaced implants near the nasal cavity using the Caldwell-Luc technique (anterior window) with noted difficulty to differentiate between the nasal cavity and maxillary sinus. Implant displacement into the maxillary sinus roof near the orbital floor can be technically challenging due to surgical access and the proximity of vital anatomical structures. Bleeding from the pterygoid venous plexus was profound with posterior lateral approach.

Discussion: The choice of the appropriate surgical approach to retrieve displaced dental implants into the maxillary sinus depends on the implant's location and the surrounding vital anatomical structures.

\section{Introduction}

Poor bone quality and quantity as well as proximity to vital anatomical structures, e.g. maxillary sinus, leads to the surgery of the posterior maxilla being associated with high level of complications. Soft bone and/or overpreparation of implant site may result in primary instability and increase risk of sinus perforation with displacement of dental implant into the sinus ${ }^{1,2}$

There are many senariors regrading the migration of the dental implants into the posterior part of the maxilla. The implant may displace inside the sinus during the surgey due to insufficient primary stability of the implant during implantation or due to bone resorption around the implant in the following months postoperatively. This can lead to implant migration toward the maxillary sinus due to the forces created by the mechanism of mastication. The critical time is usually during the first three postoperative weeks when the bone is undergoing remodeling; hence the implant stability may be compromised ${ }^{3}$.

Insertion of dental implants without sinus lifting procedure in highly pneumatized sinuses can lead to implant migration into the sinus floor. The existence of untreated antral base perforation following alveolar sinus lifting facilitates more distant implant displacement. Such kind of displacement might not be limited to the floor but other locations in the sinus. In some cases, the displacement may not be even limited to the maxillary sinus, but other structures including the paranasal sinuses. Such diversity in the displacement locations warrants the use of different surgical approaches to retrieve these implants ${ }^{4,5,6}$.

Different endoscopic and non-endoscopic sinus surgeries have been reported over the years to remove displaced implants into the maxillary sinus. However to our knowledge, no study has yet investigated the efficacy of different intraoral approaches. In this case series, four anatomic forms of displacement were discussed and a modified and non-modified Caldwell-Luc surgical approaches performed to retrieve these implants. The aim of the present study was to evaluate advantages and the disadvantages of different surgical approaches used to retrieve migrating dental implants from inside the maxillary sinus.

\section{Patients And Methods}

This prospective clinical series involved 11 patients who presented to the Oral and Maxillofacial Unit, Yarmouk Dental University College, IRAQ with displaced dental implants inside the maxillary sinus and other associated symptoms. The study was approved by the local ethics committee, and all patients signed an informed consent to have treatment and to be included in this study. Implant migration was identified in 5 male and 3 female patients, with patients age range of 35-56 years. Our data showed that two patients presented within the first 24 hours of displacement, 8 patients presented within the first 8 weeks of implant placement, 
and one presented 6 months after loading. All the patients exhibited unremarkable medical history. Five of the patients were chronic smokers and two drank alcohol socially (non-chronic). The group demographics has been highlighted in Table 1.

Table 1

Demographic information

\begin{tabular}{|c|c|c|c|c|c|c|c|}
\hline Variable & Gender & Age & Smoking & Alcohol & ASA & Location & Sinus lifting \\
\hline Patient 1 & Male & 38 & Yes & No & I & 1st PM & By implant* \\
\hline Patient 2 & Male & 55 & No & Yes & II & 2nd PM & By implant \\
\hline Patient 3 & Male & 45 & Yes & No & I & 1st PM & By implant \\
\hline Patient 4 & Male & 51 & Yes & No & I & 2nd PM & Crestal $\neq$ \\
\hline Patient 5 & Male & 53 & No & Yes & I & 1st M & Crestal \\
\hline Patient 6 & Male & 56 & Yes & No & II & 2nd PM & Crestal \\
\hline Patient 7 & Female & 35 & No & No & I & 1st M & Crestal \\
\hline Patient 8 & Female & 39 & Yes & No & II & 2nd M & Crestal \\
\hline Patient 9 & Female & 41 & No & No & 1 & 1st M & Crestal \\
\hline Patient 10 & Female & 39 & No & No & 1 & 1st M & Crestal \\
\hline Patient 11 & Female & 40 & No & No & I & $1 \mathrm{st} \mathrm{M}$ & Crestal \\
\hline \multicolumn{8}{|c|}{ By implant*: Sinus lifting by the implant's apex without bone graft. } \\
\hline
\end{tabular}

Previous to their presentation, eight patients underwent crestal sinus lifting using the osteotome with simultaneous bone graft and implant placements, and the other three had sinus lifting by the implant without bone graft. All the cases, except one, were referred to our unit. An OPG (orthopantomogram) with CBCT (cone beam computed tomography) were used to investigate the displaced dental implant anatomical location.

Four main classical approaches have been used for implant retrieval depending on its location: an intracrestal (lower window) approach through the implant insertion site (Fig. 1), Caldwell-Luc upper procedure (anterior approach) through bony window near the canine fossa (Fig. 2), an upper lateral approach (ULA) under the zygomatic buttress for a displaced implant in the superior aspect of the sinus (Fig. 3) and a posterior lateral approach (PLA) for a displaced implant in the posterior aspect of the sinus (Fig. 4). In the latter approach, the posterior part of the lateral wall of the maxillary sinus was breached by making a window by Christmas tree round bur near and above the maxillary tuberosity.

Antimicrobial prophylaxis was issued (Amoxicillin $1 \mathrm{gm} \mathrm{BD} \mathrm{for} \mathrm{5/7,} \mathrm{with} \mathrm{first} \mathrm{dose} \mathrm{to} \mathrm{be} \mathrm{taken} 1$ hour preoperatively. The decision for the surgical approach depended mainly on the surgeon's experience, the anatomical location of displaced implant and the availability of a surgical endoscope in our unit. Local anesthesia by infiltration with Lidocaine/epinephrine was carried out. Then a crestal incision was made followed by a raising a full thickness mucoperiosteal flap, with the aim to expose the anterior-lateral wall of the maxilla from the canine to the molar region for the Caldwell-Luc approach (CLA). Intntraoral x-rays were used during the operation to define the anterior boundary of the maxillary sinus and to differentiate between maxillary sinus and nasal cavity.

The upper lateral antrostomy was carried out at the premolar-molar region, the flap extended more superiorly, bone removed and the sinus membrane was raised and incised to allow removal of dental implant. Suturing the membrane was performed with a 6 - 0 Vicryl suture. A resorbable membrane was used to protect the elevated sinus membrane. A plastic surgical aspirator tip was fitted tightly into the access window in case of far displaced implants. The sinus was filled with saline, and the patient was placed in a lateral position on the dental chair with the sinus involved in surgery being on the underside. The saline acted as a medium to bring out the implant. 
All the surgeries were carried out by a single experienced operator who, later on, was asked to rate the surgical complexity of each approach as easy, moderate, difficult or highly difficult with the possible explanation. The time required to gain access and remove the implants was also recorded as well as early and late postoperative complications. A questioner was given to each patient at the end of surgery. Visual analogue scale (VAS) was used to evaluate the severity of the pain from day 1 to day 7 postoperative and as reported by the patient. A foul taste, post nasal drip and nasal obstruction were evaluated at day 7 . In addition of the questioner, all the patient were called for a review appointment at day 7,10 and 14 to check wound status and to confirm the ratings in the questioner were understood and written properly. Postoperative follow-ups were scheduled at weekly intervals from day 14 up to 3 months to monitor the healing process, record outcome and manage any complications.

For facial swelling and facial paresthesia, both the operator and patients' feedback were used for the final rating. Infra orbital nerve paresthesia was tested with twopoint discrimination test and cotton wick test on the buccal gingiva and skin over the zygomatic bone. Sutures were removed 2 weeks following surgery. Patients were recommended soft diet for 4 weeks, and oral hygiene instructions were provided. Non-steroidal anti-inflammatory drugs (Ibuprofen $600 \mathrm{mg}$ TDS for 5/7) and nasal decongestant (Psedoephedrine nasal drop, BD for 3/7) were issued to each patient.

\section{Results}

The average time required to remove the implants form the sinus using the low window (intracrestal approach) was 11.5 minutes compared with 22 minutes for anterior lateral approach, 35 minutes for the upper lateral and 42 minutes for the posterior lateral approach. Regarding the surgical complexity of the surgery, three cases of low window approach was rated as "easy" surgery while one case rated as "moderate" surgery. For the Anterior-lateral window approach (CLA), two cases were rated as "difficult" and one was rated as "moderate" surgery due to difficulty to differentiate between the nasal cavity and maxillary sinus. Highly difficult was evaluated in one surgical access in the posterior-lateral window approach due to profound bleeding and difficulty to locate the displaced implant. Difficult surgeries were encountered in handling upper-lateral window due to the thickness of the zygomatic bone (Table 2). 
Table 2

Summery of the surgical approaches and the outcome of the different techniques.

\begin{tabular}{|c|c|c|c|c|c|c|c|c|c|}
\hline Variable & $\begin{array}{l}\text { Surgical } \\
\text { access }\end{array}$ & $\begin{array}{l}\text { Time } \\
\text { required } \\
\text { to } \\
\text { remove } \\
\text { implant }\end{array}$ & $\begin{array}{l}\text { Surgical } \\
\text { complexity }\end{array}$ & Pain * & Foul taste & $\begin{array}{l}\text { Post } \\
\text { nasal } \\
\text { dipping }\end{array}$ & $\begin{array}{l}\text { Facial } \\
\text { swelling }\end{array}$ & $\begin{array}{l}\text { Nasal } \\
\text { obstruction }\end{array}$ & $\begin{array}{l}\text { Facial } \\
\text { paresthesia }\end{array}$ \\
\hline $\begin{array}{l}\text { Patient } \\
1\end{array}$ & LW & $\begin{array}{l}10 \\
\text { minutes }\end{array}$ & Easy & Mild & Insignificant & $+v e$ & Mild & Mild & $-V e$ \\
\hline $\begin{array}{l}\text { Patient } \\
2\end{array}$ & LW & $\begin{array}{l}15 \\
\text { minutes }\end{array}$ & Moderate & Mild & Insignificant & -ve & Mild & Mild & $-V e$ \\
\hline $\begin{array}{l}\text { Patient } \\
3\end{array}$ & LW & $\begin{array}{l}8 \\
\text { minutes }\end{array}$ & Easy & Mild & Insignificant & -ve & Moderate & Mild & $-V e$ \\
\hline $\begin{array}{l}\text { Patient } \\
4\end{array}$ & LW & $\begin{array}{l}13 \\
\text { minutes }\end{array}$ & Easy & Mild & Insignificant & -ve & Moderate & Mild & $-V e$ \\
\hline $\begin{array}{l}\text { Patient } \\
5\end{array}$ & ALW & $\begin{array}{l}25 \\
\text { minutes }\end{array}$ & Moderate & Mild & Significant & $+v e$ & Moderate & Mild & $-V e$ \\
\hline $\begin{array}{l}\text { Patient } \\
6\end{array}$ & ALW & $\begin{array}{l}20 \\
\text { minutes }\end{array}$ & Difficult & Moderate & Significant & $+\mathrm{ve}$ & Moderate & Moderate & $\begin{array}{l}\text { First } 4 \\
\text { weeks }\end{array}$ \\
\hline $\begin{array}{l}\text { Patient } \\
7\end{array}$ & ALW & $\begin{array}{l}22 \\
\text { minutes }\end{array}$ & Difficult & Mild & Significant & $+v e$ & Moderate & Moderate & $\begin{array}{l}\text { First } 7 \\
\text { weeks }\end{array}$ \\
\hline $\begin{array}{l}\text { Patient } \\
8\end{array}$ & ULW & $\begin{array}{l}35 \\
\text { minutes }\end{array}$ & Difficult & moderate & $\begin{array}{l}\text { Highly } \\
\text { significant }\end{array}$ & $+v e$ & Sever & Sever & $\begin{array}{l}\text { First } 9 \\
\text { weeks }\end{array}$ \\
\hline $\begin{array}{l}\text { Patient } \\
9\end{array}$ & ULW & $\begin{array}{l}35 \\
\text { minutes }\end{array}$ & Difficult & moderate & Significant & $+v e$ & Moderate & Moderate & $-V e$ \\
\hline $\begin{array}{l}\text { Patient } \\
10\end{array}$ & PLW & $\begin{array}{l}40 \\
\text { minutes }\end{array}$ & $\begin{array}{l}\text { Highly } \\
\text { difficult }\end{array}$ & Moderate & Significant & $+v e$ & Moderate & Moderate & $-V e$ \\
\hline $\begin{array}{l}\text { Patient } \\
11\end{array}$ & PLW & $\begin{array}{l}44 \\
\text { minutes }\end{array}$ & Difficult & moderate & Significant & $+v e$ & Moderate & Mild & $-V e$ \\
\hline \multicolumn{10}{|c|}{ LW: Lower window } \\
\hline \multicolumn{10}{|c|}{ ALW: Anterior-lateral window } \\
\hline \multicolumn{10}{|c|}{ ULW: Upper-lateral window } \\
\hline \multicolumn{10}{|c|}{ PLW: Posterior-lateral window } \\
\hline
\end{tabular}

The pain from the day of the surgery till day 7 was "mild" in lower window approach, the pain was "moderate" following implants removal from upper lateral and posterior lateral approaches. Early postoperative complications involved three patients developing temporary paraesthesia, in two cases the paraesthesia was noted in the buccal vestibule following the CLA approach near the canine fossa. The maximum time for the recovery from the paraesthesia was 9 weeks and related to upper lateral approach in which numbness at the site of the nose, upper lip and skin over the zygomatic bone were involved. Nasal obstruction scored in 5 patients as moderate on day 7 postoperatively and resolved by day 14. In one patient the nasal obstruction was sever, the patient also suffered highly significant foul taste with post nasal drip in mouth and significant facial swelling. In this case, upper lateral approach was followed to remove the displaced implant and the patient reported full resolution of the nasal obstruction and post nasal drip after 4 weeks. The foul taste were insignificant in the low window approach cases, in the same approach no detectable post nasal drip were reported in 3 cases out of 4 . Facial swelling following the surgery were sever in one case in which the swelling extended to the lower eyelid causing partial eye closure, moderate in eight cases and mild in two cases which resolved completely in all cases in day 10-14. 
At the end of the month 3 after the surgery, all the patients reported sinus free symptoms. OPG x-rays showed no evidence of any sinus fluid or cyst. Digital palpation of the bone area where the surgery delivered showed a clinical detectable depression in the area of CLA in two patients. Moderate horizontal and vertical alveolar bone resorption and shrinkage were associated with lower window approach (three cases). Vestibular shortening and visible scare was detected in upper lateral approach but the patient was not troubled.

\section{Discussion}

This study has some limitations. First, the sample size was too small to establish the effectiveness of single best approach. Second, the range of maxillary sinus status between the different groups was not the same. Although further study of a large population is needed to establish definite indications and limitations of each approach, our study offers a comparison between the four approaches, showing that surgical access is comparable.

Migration of dental implant into the maxillary sinus is considered iatrogenic because it mostly happens due to lack of proper planning of the surgical procedures. Varol et $\mathrm{al}^{\beta}$ and Chappuis et $a^{\beta}$ listed some causes of displacement during surgery, including less experienced surgeons, poor primary implant stability, unsuccessful bone regeneration following previous maxillary sinus floor elevation, and implantation without treatment of perforation caused by implant drilling. In particular, poor primary stability causes implant micromovement, which prevents clot formation and revascularization and makes new bone formation more difficult. All of these factors can lead to poor implant fixation and failure to obtain osseointegration, resulting in late implant displacement ${ }^{9,10,11}$.

Consequently, an implant displaced in the maxillary sinus often result in serious complications such as maxillary sinusitis, nasal obstruction, bony necrosis, foreign body aspiration, and migration into deeper sinus cavities. Therefore, a migrated implant in the maxillary sinus should be removed as early as possible to prevent further risks of worsening symptoms and uneventful sequelae ${ }^{12,13,14}$. Caldwell Luc surgical approach has been one of the most favorable classical approaches to the maxillary sinus due to its ease of access and visibility. However, several postoperative complications have been reported following a CLA, such as postoperative maxillary cysts (POMC) and a high rate of relapse of sinus symptoms, which were thought to be induced by decreased sinus volume, resulted from the inferior osteotomy ${ }^{15}$.

On the other hand, intracrestal approach is recommended by many clinicians due to the direct access, rapid recovery of sinus functions, less invasiveness, and flexibility. The crestal approach requires less bone volume removal and less surgical trauma as the bone is less dense and more trabecular than the lateral wall of the maxillary sinus ${ }^{16,17}$. However, this blind procedure may lead to unsatisfactory results when the material is entrapped in the undercut of the sinus, and often leads to undesirable postoperative depression of the alveolar ridge due to the procedure of enlarging the socket for a suction tube ${ }^{18}$.

In our study, the intracrestal approach was associated with less pain and less facial swelling compared with CLA. The approach was distant from the infraorbital nerve, the main sensory nerve in the labial gingiva and upper lip, and there were no neuropathy reported in the present study following the intracrestal approach. The Caldwell-Luc approach is the gold standard for access to the maxillary sinus for treatment of various problems, including retrieval of foreign bodies. There are some disadvantages encountered in this approach in the current research include the resulting bone defect of the lateral antral wall and injury of the mucosal branches of infraorbital nerve. Our findings related to the complications related to CLA were in accord of previous studies ${ }^{19,20,21}$.

A more serious nerve injury reported in one case associated with upper lateral approach, the facial paresthesia involved both the oral mucosa and the skin on the lateral side of the nose. The upper lateral antrostomy was carried out at the premolar-molar region, the flap extended more superiorly to expose and remove the thick zygomatic bone using round bur might be the possible causes to injure the infra orbital nerve. The time required to remove the implant was 35 minutes and the surgery scored as difficult due to difficulty in removing the bone and this might be the possible cause of the pain and severity of the facial swelling that happened after the surgery.

The localization of the implant inside the sinus is extremely difficult due to the large size of the sinus. The average capacity of the maxillary sinus varies from 9.5 to $20 \mathrm{~mL}$ and averages $14.75 \mathrm{~mL}$. The average dimensions are $3.75 \mathrm{~cm}$ vertically, $2.5 \mathrm{~cm}$ mediolaterally and $2.5 \mathrm{~cm}$ antero-posteriorly. The sinus cavity may also extend into the zygoma. Thus, a sinus can usually be filled with 10 to $20 \mathrm{~mL}$ of lavage saline $22,23,24$. Considering the position of the implant in the maxillary sinus, it is often difficult to 
visualize the implant. In particular, when the implant is located on the superior or posterior aspects. It usually a challenge to remove through the intracrestal or Caldwell Luc approach.

Posterior displacement of the implant is a real challenge due to accessibility. Dryer and Conrad ${ }^{25}$ reported a case regarding surgical complications related to implants in the pterygomaxillary region. In their report, the dental implant was removed with a CT-guided endoscope transnasally. In current study, two of the implants displaced into the posterior aspect of the maxillary sinus was retrieved by posterior lateral window approach. The surgery took 42 minutes as an average despite the soft bone that existed in this area which removed easily. The longer time taken to remove the implant was attributed to the bleeding from the pterygoid venous plexus. Another challenge in this approach was difficulty to locate the implant as the implant change its position according to patient position. It is worth knowing that this is the only case where the surgery done within the first 24 hours of the displacement.

Immediate or early removal of the displaced implants is indicated to prevent infectious complications due to the contact of the implant with the mucosa of the sinus interior ${ }^{26}$. However, immediate displacement of the implant deep inside the sinus after sinus lifting with unnoticeable membrane perforation render the implant free and changing positions due to non attachment status of the implant to the sinus membrane. Thus the authors recommend leaving the implant in situ for 2 weeks to allow granulation tissue encapsulation.

\section{Conclusion}

The choice of the most appropriate surgical approach to retrieve a displaced dental implant into the maxillary sinus depends on the implant's location inside the sinus. The most straightforward approach is either through the implant site or by creating a window in the lower-lateral wall of the maxillary sinus. To confirm the efficacy of different intraoral approaches, a larger cohort with long-term follow-up study is recommended.

\section{List Of Abbreviations}

OPG: Orthopantomogram; СBCT: Cone beam computed tomography; POMC: postoperative maxillary cysts; VAS Visual analogue; CLA: Caldwell-Luc approach; ULA: upper lateral approach; PLA: Posterior lateral approach.

\section{Declarations}

\section{Ethics}

Ethical approval has been obtained from Yarmouk Dental University College (File: 382K-2018)

\section{Consent}

All the patients in this study provided informed consent which was approved by the same ethics committee of Yarmouk Dental University College

\section{Availability of data and materials}

The authors declare that all the data supporting the findings of this study are available within the article

\section{Competing interests}

The authors declare that they have no competing interests

\section{Funding}

The article processing charges are funded by the authors

\section{Authors' contributions}


Z Hamddon, N Mahmood, K Naeim and A Qais were involved in the conduction and date gathering of the study. W Kheder has been involved in drafting the manuscript, A Abdul Sattar was involved in revising the manuscript, W Talat and W Jerjes made a significant intellectual contribution to result evaluation, critical revision and paper compilation.

\section{Acknowledgements}

Not applicable

\section{References}

1. Galindo-Moreno P, Padial-Molina M, Sánchez-Fernández E, Hernández-Cortés P, Wang HL, O'Valle F. Dental implant migration in grafted maxillary sinus. Implant Dent. 2011;20(6):400-405.

2. Galindo P, Sánchez-Fernández E, Avila G, Cutando A, Fernandez JE. Migration of implants into the maxillary sinus: two clinical cases. Int J Oral Maxillofac Implants. 2005;20(2):291-295.

3. Jeong KI, Kim SG, Oh JS, Jeong MA. Displaced implants into maxillary sinus: report of cases. Implant Dent. 2014;23(3):245249.

4. Haben CM, Balys R, Frenkiel S. Dental implant migration into the ethmoid sinus. J Otolaryngol. 2003;32(5):342-344.

5. Felisati G, Lozza P, Chiapasco M, Borloni R. Endoscopic removal of an unusual foreign body in the sphenoid sinus: an oral implant. Clin Oral Implants Res. 2007;18(6):776-780.

6. Cascone P, Ungari C, Filiaci F, Gabriele G, Ramieri V. A dental implant in the anterior cranial fossae. Int J Oral Maxillofac Surg. 2010;39(1):92-93.

7. Varol A, Türker N, Göker K, Basa S. Endoscopic retrieval of dental implants from the maxillary sinus. Int J Oral Maxillofac Implants. 2006;21(5):801-804.

8. Chappuis V, Suter VG, Bornstein MM. Displacement of a dental implant into the maxillary sinus: report of an unusual complication when performing staged sinus floor elevation procedures. Int J Periodontics Restorative Dent. 2009;29(1):81-87.

9. Brunski JB. In vivo bone response to biomechanical loading at the bone/dental-implant interface. Adv Dent Res. 1999;13:99119.

10. Gerstenfeld LC, Cullinane DM, Barnes GL, Graves DT, Einhorn TA. Fracture healing as a post-natal developmental process: molecular, spatial, and temporal aspects of its regulation. J Cell Biochem. 2003;88(5):873-884.

11. Davies JE. Mechanisms of endosseous integration. Int J Prosthodont. 1998;11(5):391-401.

12. Barone A, Santini S, Sbordone L, Crespi R, Covani U. A clinical study of the outcomes and complications associated with maxillary sinus augmentation. Int J Oral Maxillofac Implants. 2006;21(1):81-85.

13. Amble FR, Lindberg SO, McCaffrey TV, Runer T. Mucociliary function and endothelins 1, 2, and 3. Otolaryngol Head Neck Surg. 1993;109(4):634-645.

14. Westrin KM, Stierna P, Carlsöö B, Hellström S. Mucosal fine structure in experimental sinusitis. Ann Otol Rhinol Laryngol. 1993;102(8 Pt 1):639-645.

15. Chiapasco M, Felisati G, Maccari A, Borloni R, Gatti F, Di Leo F. The management of complications following displacement of oral implants in the paranasal sinuses: a multicenter clinical report and proposed treatment protocols. Int $\mathrm{J}$ Oral Maxillofac Surg. 2009;38(12):1273-1278.

16. Fusari P, Doto M, Chiapasco M. Removal of a dental implant displaced into the maxillary sinus by means of the bone lid technique. Case Rep Dent. 2013;2013:260707.

17. Sadda R. Crestal approach for removing a migrated dental implant from the maxillary sinus: a case report. Gen Dent. 2015;63(1):78-79.

18. Archer WH. Oral and Maxillofacial Surgery. Vol II. 5th ed. Philadelphia: WB Saunders; (1975), p.1605-1627.

19. Närkiö-Mäkelä M, Qvarnberg Y. Endoscopic sinus surgery or Caldwell-Luc operation in the treatment of chronic and recurrent maxillary sinusitis. Acta Otolaryngol Suppl. 1997;529:177-180.

20. Penttilä MA, Rautiainen ME, Pukander JS, Karma PH. Endoscopic versus Caldwell-Luc approach in chronic maxillary sinusitis: comparison of symptoms at one-year follow-up. Rhinology. 1994;32(4):161-165.Goodman W. S. (1976). The Caldwell-Luc 
procedure. Otolaryngologic clinics of North America, 9(1), 187-195.

21. Goodman WS. The Caldwell-Luc procedure. Otolaryngol Clin North Am. 1976;9(1):187-195.

22. Conforte JJ, Ponzoni D. Sinusitis Due to the Presence of a Dental Implant Inside the Maxillary Sinus. J Craniofac Surg. 2018;29(6):e591.

23. Cable HR, Jeans WD, Cullen RJ, Bull PD, Maw AR. Computerized tomography of the Caldwell-Luc cavity. J Laryngol Otol. 1981;95(8):775-783

24. Potter GD. Sinus anatomy and pathology. Bull N Y Acad Med. 1981;57(7):591-594.

25. McDonnell D, Esposito M, Todd ME. A teaching model to illustrate the variation in size and shape of the maxillary sinus. $J$ Anat. 1992;181 ( Pt 2)(Pt 2):377-380.

26. Dryer RR, Conrad HJ. Displacement of a Dental Implant into the Pterygoid Fossa: A Clinical Report. J Prosthodont. 2019;28(9):1044-1046.

\section{Figures}

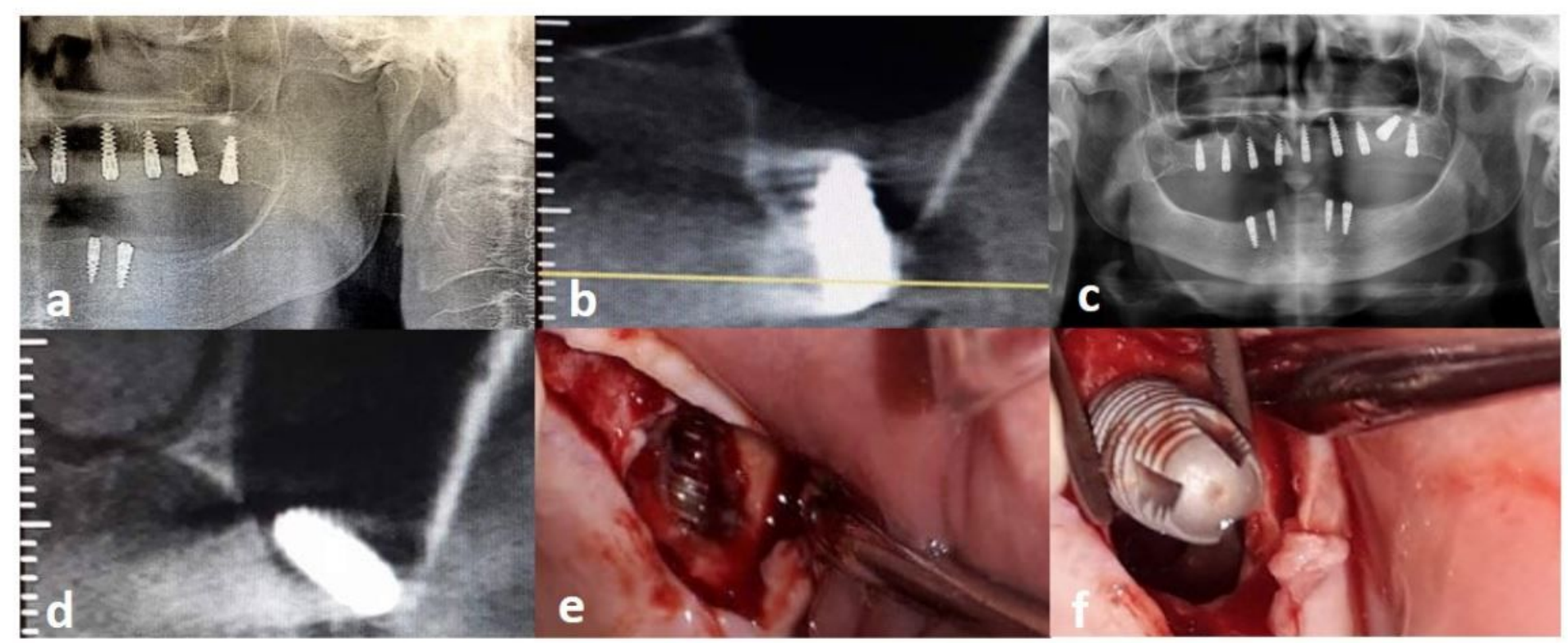

\section{Figure 1}

Preoperative X-ray with vertical residual bone in the upper posterior maxillary area of $4 \mathrm{~mm}(\mathrm{a})$, immediate coronal CBCT showing implant surrounded by bone graft (b). Implant migration three weeks after crestal sinus lifting (c,d). Implant migration three months after bone graft surgery. Envelope crestal incision, surgical window in the alveolar bone followed by implant catching and retrieval through transalvoelar approach $(e, f)$. 


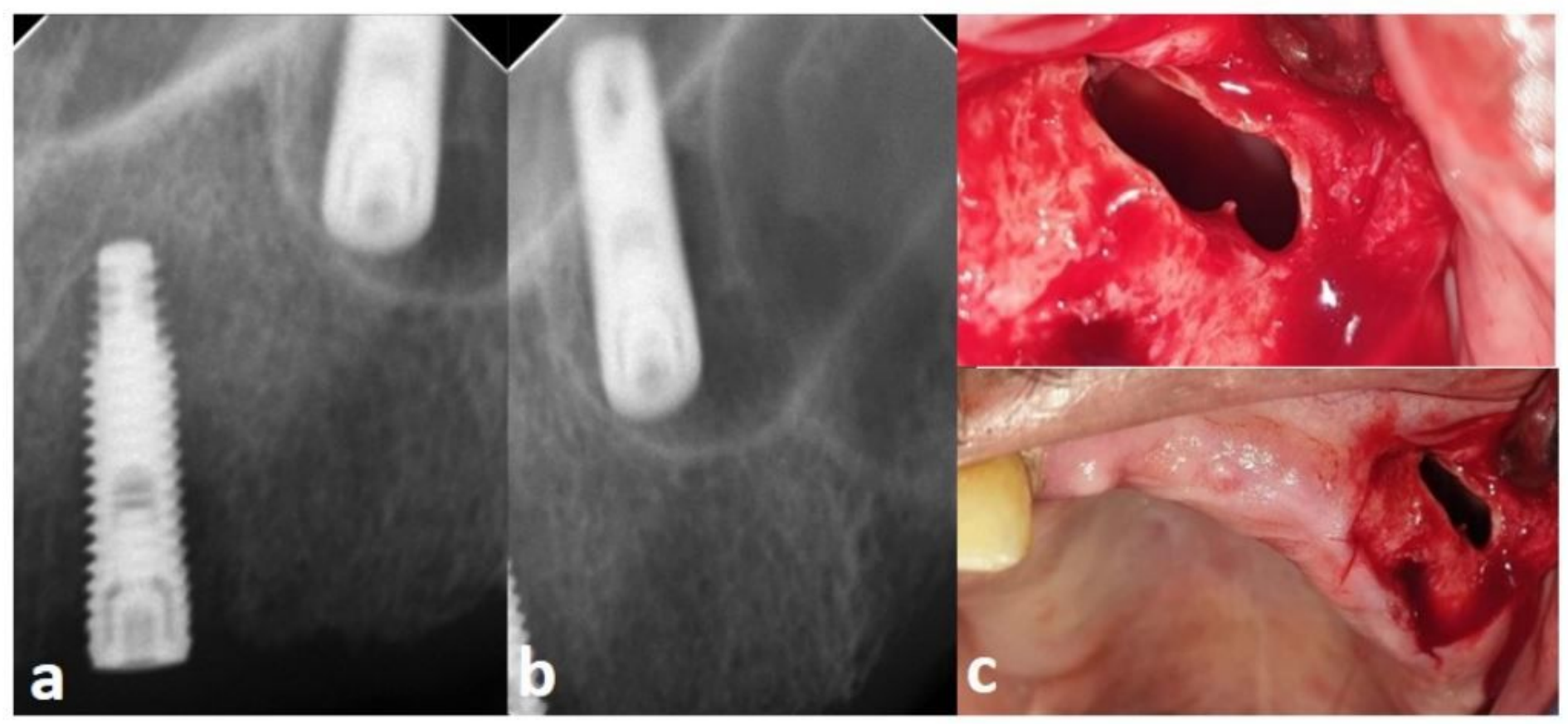

\section{Figure 2}

Dental implant displacement toward the most anterior part of the sinus and near to the nasal cavity $(a, b)$. Caldwell Luc operation near the canine fossa with three sided flap and wide bone window to retrieve the implant (c).

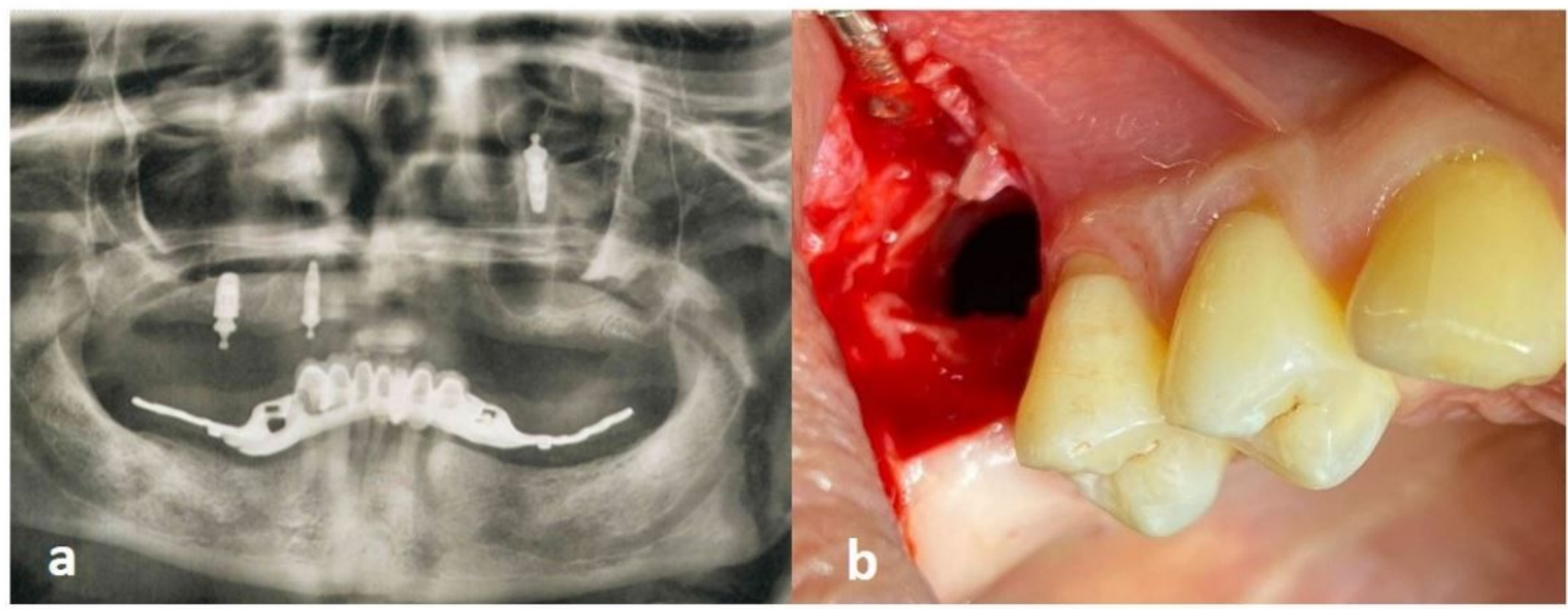

\section{Figure 3}

An X-ray showing a dental implant with ball abutment displaced toward the superior part of the maxillary sinus 6 months after function (a). Upper lateral surgical approach to access displaced implant in the superior part of the sinus using two sided flap. 


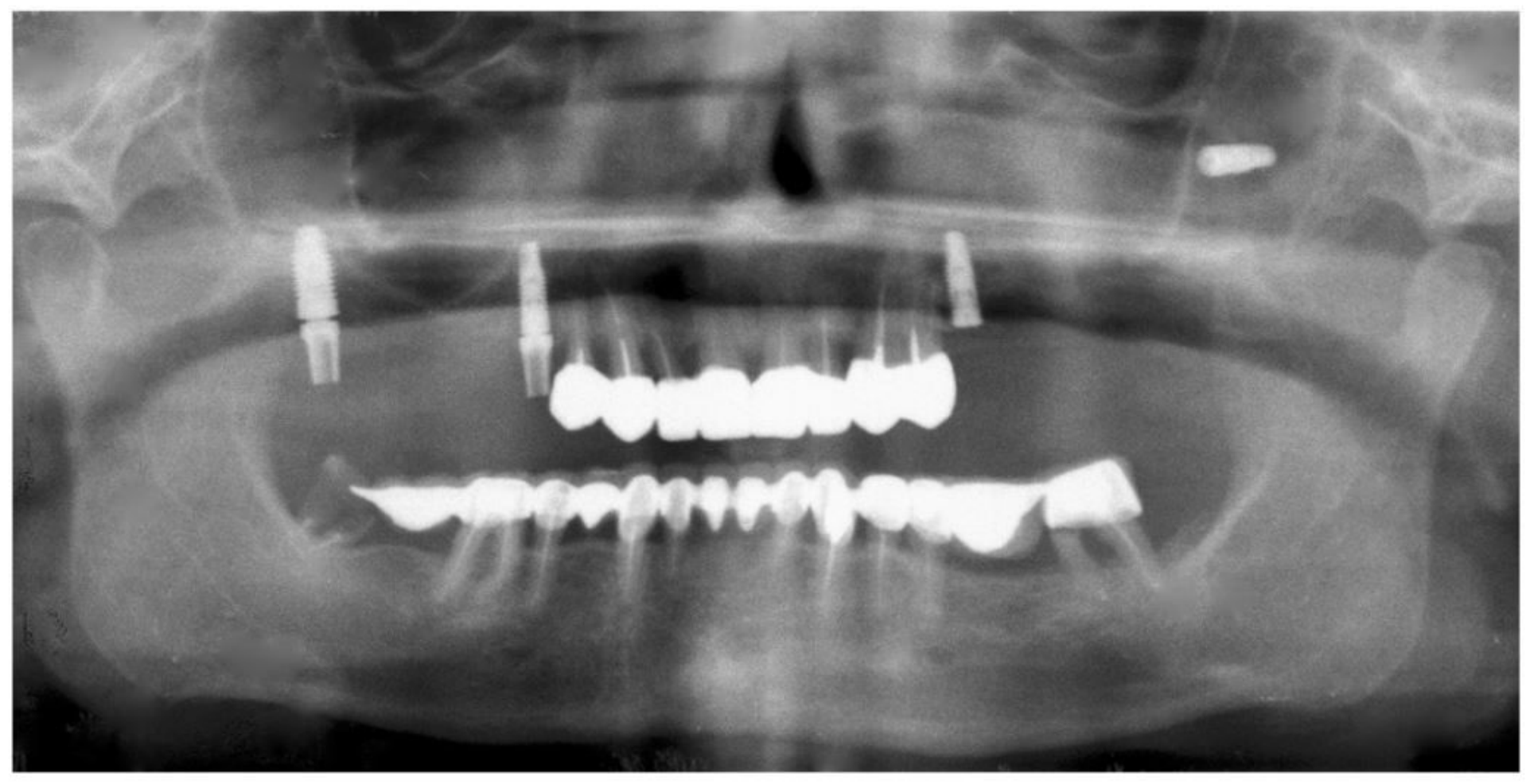

Figure 4

Implant displacement in the most posterior part of the sinus. 